\title{
Household heating and cooling energy use in the northeast USA: comparing the effects of climate change with those of purposive behaviors
}

\author{
Nicholas Shorr ${ }^{1, *}$, Raymond G. Najjar ${ }^{2}$, Anthony Amato ${ }^{3}$, Steve Graham ${ }^{4}$ \\ ${ }^{1}$ Pennsylvania Resources Council, Pittsburgh, Pennsylvania, 15203, USA \\ ${ }^{2}$ Department of Meteorology, Pennsylvania State University, University Park, Pennsylvania 16802, USA \\ ${ }^{3}$ Eastern Research Group (ERG), Lexington, Boston Massachusetts 02110, USA \\ ${ }^{4}$ Population Institute, Pennsylvania State University, University Park, Pennsylvania 16802, USA
}

\begin{abstract}
For most residents in northern temperate zones, the most direct economic impact of global climate change is likely to be changes in home heating and cooling (HC) expenses, estimates of which should be of widespread interest. These residents are increasingly likely to make HC decisions (e.g. switches to electric heat, thermostat settings, conservation investments and behavioral change) in a wider context. The question turns from 'will projected climate change reduce my HC bills?' to 'how will projected climate change, with and without these various actions, affect my HC bills, my total energy use and my greenhouse gas emissions?' We modeled these 3 variables (HC expense, energy use and GHG emissions) on average households in 13 states in the northeastern United States under projected climate change alone, and under projected climate change with 3 modeled choices: increasing use of air-conditioners (AC); switching from petroleum-derived fuels to electric heating; and investing in insulation and efficiency upgrades. High climate change was projected to reduce annual $\mathrm{HC}$ expenses for average households in each state, the effect increasing through the century. These savings varied with ratios of heating degree-day to cooling degree-day changes, and with ratios of petroleum-derivative heating to electric heating households; both ratios varied along a north-south gradient in this region. Increasing AC use increased total energy use and $\mathrm{CO}_{2}$ emissions more than it did expenses. Fuel-switching increased the first 2 more than it reduced the third. Upgrades provided the greatest savings in all 3 variables under low and high climate change. Effective energy policies and effective communication with energy users both require require explicit investigation of $\mathrm{HC}$ intensities at the household level, and modeling of conservation behaviors as well as purchased upgrades.
\end{abstract}

KEY WORDS: Climate change - Energy use - Heating $\cdot$ Cooling ' Household $\cdot$ Economics · Conservation $\cdot$ Consumer decisions

\section{INTRODUCTION}

Of the various impacts of projected climate change in northern latitudes (e.g. Kovats \& Ebi 2006, Wu et al. 2007), changes in home heating and cooling (HC) energy use are likely to directly affect the greatest number of residents. Given the growing awareness of both climate change and rising energy prices, it is likely that many northern inhabitants have come to think 'well, at least global warming will lower my heating bills!', and would be interested in seeing what research has to say on the matter.

*Address for correspondence: 7049 Willard Street, Pittsburgh, Pennsylvania 15208, USA. Email: nshorr@verizon.net
Several researchers have modeled the effect of projected climate change (CC) on residential heating and cooling energy use (CC > HC) at the aggregate level for US states (Belzer et al. 1996, Sailor \& Munoz 1997, Sailor et al. 1998, Sailor 2001, Belzer \& Cort 2004, Amato et al. 2005) and entire countries (e.g. Rosenthal \& Gruenspecht 1995, Hadley et al. 2004, Christenson et al. 2006, Huang 2006). While these findings can help energy providers and policymakers prepare for future demand more adequately and cost effectively, it is at the household level that $\mathrm{CC}>\mathrm{HC}$ estimates are most relevant for consumer decisions. 
Managers of households, owners and renters, may use these estimates in making decisions regarding investments in HC upgrades (better insulation, more efficient components), changes in everyday behaviors (e.g. thermostat settings, use of thermal curtains) and fuel-switching to cheaper energy sources. They may also be useful to those with a professional interest in the aggregate consequences of these household decisions. Staff in programs that assist or encourage households in reducing energy consumption, utility bills, greenhouse gas (GHG) emissions or air pollution may use them in determining the most effective way of allocating scarce public funds, and in public communication efforts (e.g. as part of web-based calculators).

Two features of $\mathrm{CC} / \mathrm{HC}$ relationships suggest that consideration of these estimates may provide an important opportunity for public communication, building on consumers' initial curiosity (i.g. 'won't climate change lower my heating bills?'). First, if high CC reduces $\mathrm{HC}$ expenses for most households in northern latitudes, it would be a striking example of interregional asymmetries between responsibility for and impacts from CC. Researchers have found that populations that have contributed and continue to contribute most to climate change on a GHG per capita emissions basis are likely to receive relatively benign impacts from it, while its most seriously negative impacts (e.g. the worst droughts, heat-waves and flooding) are likely to hit those who have made and make considerably lower contributions to it (Muylaert et al. 2004, Hohne \& Blok 2005, Mendelsohn et al. 2006). That the former group is dramatically more affluent, on average, than the latter compounds the asymmetry.

Second, HC energy use has a uniquely reciprocal relationship with CC. While residential heating and cooling generate only $7 \%$ or so of total US GHG emission, they are, along with our use of private automobiles $(17 \%)$ and other home electricity uses $(9 \%$, all percentages derived from EPA 2006), the 'contributions' over which individual households have the greatest direct control. There is some evidence that knowledge of the causes of climate change are an important predictor of willingness to act to reduce these contributions, even independent of perceived level of certainty about climate change or the seriousness of its effects (Bord et al. 2000, O'Connor et al. 2002).

As more people learn of these relationships, more are likely to become curious and concerned not only about the effects climate change on their $\mathrm{HC}$ expenses but also about the total energy used by and GHG emissions from their household heating and cooling and about ways they might reduce all 3. To be of greatest utility in householders' decision-making, a CC > HC model should include several behavioral options and estimate how they would affect these 3 impacts of con- cern (HC expense, energy use and GHG emissions). Here we model reasonable maximum climate change impacts on heating and cooling energy use over the rest of the century in the residential sector, at the level of the average household in each of 13 states in the northeastern US (ME, VT, NH, NY, MA, RI, CT, PA, WV, NJ, MD, DE and VA). We apply projected usages under high climate change to high energy price projections from the US Energy Information Administration (EIA), model climate change impacts on $\mathrm{HC}$ total energy and $\mathrm{CO}_{2}$ emissions, and compare all 3 impacts to those entailed by 2 purposive behaviors of householders: switching from petroleum-derived heating fuels to lower-cost electric heat and HC upgrading in insulation and more efficient components.

\section{METHODS}

The amount of energy a household uses for heating (cooling) over a period of time is a product of how cold (hot) it has been over that period times how much energy it has taken to heat (cool) the household from that 'coldness' ('hotness'). 1 The indicies of heating (cooling) degree-days (HDD and CDD) have been developed as precise measures of 'how hot (or cold) it has been'. These differ from a comfortable temperature: the 'balance point' or 'base temperature', conventionally $65^{\circ} \mathrm{F}\left(18.33^{\circ} \mathrm{C}\right)$; each degree deviation from the base is counted as 1 degree-day. They can be accumulated over to time, to give monthly or annual totals (Thom 1954, Diaz \& Quayle 1980). Heating (cooling) intensity (HI and $\mathrm{CI}$ ) are the amount of heating (cooling) energy consumed per HDD (CDD), determined by the volume of space that is heated or cooled, level of insulation and infiltration of thermal shell and ducts, efficiencies of furnace and air-conditioners, and behaviors affecting thermostat settings, windows, shades, etc.

Eq. (1) is a simple conceptual model from which we can identify factors that determine both the extent and valence of climate change impact on $\mathrm{HC}$ expenses, summarized in Table 1.

$$
\begin{gathered}
\mathrm{HC} \text { Expense }=(\mathrm{HDD} \times \mathrm{HI} \times \mathrm{H} \text { price })+ \\
(\mathrm{CDD} \times \mathrm{CI} \times \mathrm{E} \text { price })
\end{gathered}
$$

where $\mathrm{H}$ is heating and $\mathrm{E}$ is electricity.

Projecting any one of the variables out into the future is a highly uncertain undertaking; projecting their product might be considered a fool's errand. However,

\footnotetext{
${ }^{1}$ While relative humidity and windiness also affect heating and cooling energy use, they have proved far more difficult to capture in global climate change models and were excluded from this analysis
} 
Table 1. Factors determining climate change impacts on heating-plus-cooling expense HDD. HDD: heating degree-days; CDD: cooling degree-days

\begin{tabular}{|lcc|}
\hline & $\begin{array}{c}\text { Expected to reduce costs/ } \\
\text { increase savings }\end{array}$ & $\begin{array}{c}\text { Expected to increase costs/ } \\
\text { reduce savings }\end{array}$ \\
\hline $\begin{array}{l}\text { Degree-day change } \\
\begin{array}{l}\text { Energy intensities } \\
\text { Energy prices }\end{array}\end{array}$ & $\begin{array}{c}\text { Rate of HDD decrease } \\
\text { Heating intensity } \\
\text { Price of heating energy }\end{array}$ & $\begin{array}{c}\text { Rate of CDD increase } \\
\text { Cooling intensity } \\
\text { Price of electricity }\end{array}$ \\
\hline
\end{tabular}

we are not attempting a prediction, but rather an estimated reasonable maximum impact from anthropogenic climate change. To this end we apply a high climate change series and a high price change series. We further simplify by holding all factors contributing to heating or cooling intensity constant, with one exception. Each is a complex phenomenon; projecting any over coming decades is likely to add to rather than reduce the overall uncertainty of our results. We model one aspect of intensity change that is highly likely to occur and has been independently modeled elsewhere: increasing ownership and use of air-conditioners (AC) as CDDs increase.

\subsection{Climate change projections and degree-day calculations}

Climate model output was obtained from the online data archive associated with the Intergovernmental Panel on Climate Change (IPCC) 2000 assessment report (Cubasch et al. 2001). We used monthly temperature output for the period 1971-2100 from 7 global climate models (GCMs) run under the A2 and B2 GHG emission scenarios and processed as described in Najjar et al. (2007). These scenarios were chosen because they were available for the greatest number of models and bracket the middle range of scenarios used for the 2000 assessment. To remove model bias in current-day temperature simulations, we added the model-predicted temperature change to the current observations. To estimate a reasonable maximum impact of climate change we use the temperature projections from emissions Scenario A2 (with the higher global GHG emissions rate) $)^{2}$ and the average of the 2 GCMs with the highest projected degree-day changes for that scenario. These were CCSR (Center for Climate System Research) and CSIRO (Commonwealth Scientific and

${ }^{2}$ Scenarios A2 and B2 correspond to atmospheric $\mathrm{CO}_{2}$ levels of about 850 and 620 ppm, respectively, in 2100. Global mean temperature increases from 1990 to 2100 for A2 and B2 are 3.8 and $2.7^{\circ} \mathrm{C}$, respectively, which are averages over all of the Intergovernmental Panel on Climate Change (IPCC) models (Cubasch et al. 2001)
Industrial Research Organization) for heating degree-days and CCSR and HADC (Hadley Centre for Climate Prediction and Research) for cooling degree-days. We used the method of Thom $(1954,1966)$, as modified by the National Climatic Data Center (2003), to compute degree-days. Input to the computation was the mean (projected) temperature for each future month (through 2099) and their long-term (observed) standard deviation at each of the 187 US Historical Climate Network (HCN) weather stations in the study region. Output was the number of heating and cooling degreedays for that month and station with respect to the standard base temperature of $65^{\circ} \mathrm{F}\left(18.3^{\circ} \mathrm{C}\right)$, as well as to base temperatures that varied with state and energy source, described below. Projected degree-days were first summed for each future year and then averaged across future decades. Population-weighted state averages were computed by averaging station degree-days by climate division and utilizing the fraction of the state population (based on the 2000 census) within each division. $\underline{3}$

\subsection{Estimating heating and cooling energy sensitivities to temperature}

Elsewhere, Amato (2004) used a method developed by Belzer and colleagues (Belzer et al. 1996, D. B. Belwer \& K. A. Cort 2004 unpubl.). He regressed the natural log of monthly natural gas, heating oil, and electricity usage over the previous 16 to $23 \mathrm{yr}$ (depending on data availability) against contemporary degreedays, and did so iteratively, using degree-days calculated from a range of base temperatures at $1^{\circ} \mathrm{F}$ (ca. $17^{\circ} \mathrm{C}$ ) intervals. For each state and energy source, the base whose degree-days displayed the highest correlation $\left(\mathrm{R}^{2}\right)$ with energy usage was selected as the appropriate base. ${ }^{\underline{4}}$ We used these base temperatures, together with the monthly temperature inputs just described, to calculate state- and energy source-specific HDDs and CDDs, and then entered these degreedays into statistical models (described in Amato 2004).

\footnotetext{
${ }^{3}$ Our degree-day projections and energy usage model include District of Columbia within Maryland, but Energy Information Administration (EIA) presents their prices (both historic and projected) separately. We, therefore, weighted these prices by their respective household weights in 2005 and added the products for 'greater Maryland' heating and cooling prices ${ }^{4}$ These 'best-fit' base temperatures for the states ranged between 53 and $62^{\circ} \mathrm{F}\left(11.7\right.$ and $\left.16.7^{\circ} \mathrm{C}\right)$ for electricity, 55 and $75^{\circ} \mathrm{F}\left(12.8\right.$ and $\left.23.9^{\circ} \mathrm{C}\right)$ for heating oil and 69 and $72^{\circ} \mathrm{F}(20.6$ and $22.2^{\circ} \mathrm{C}$ ) for natural gas
} 
To determine heating and cooling use only, we first calculated a baseline (non-temperature sensitive) use for each fuel by entering zero HDD (and zero CDD for electricity) in the regression equations and then subtracted these baselines from the estimated total usages based on degree-day (DD) inputs. To convert per capita into per household usage, we multiplied the former by the statewide average number of people per household (US Census 2005). We converted all retail measures (e.g. gallons of heating oil, kwh of electricity) into GJ million British thermal units (mbtu, or MJ) by multiplying these figures by conversion factors and then summed the results to estimate the total heating energy used per household. Because up to $27 \%$ of households (depending on the state) use other heating sources (e.g. kerosene), we divided this estimated usage per household by the fraction of households using heating oil, natural gas and electricity.

\subsection{Modeling increased air-conditioner use}

Sailor \& Pavlova (2003) defined air-conditioner saturation $(S)$ as the fraction of households in a region that own and use air-conditioners. Based on data from 40 US cities, they found

$$
S=0.944-1.17 \exp (-0.00298 \times \mathrm{CDD})
$$

We multiplied our future cooling energy usage projections by the ratio of $S$ for the future ( $\left.S_{\text {future }}\right)$ to $S$ for the present day $\left(S_{0}\right)$, using Eq. (2). $S_{\text {future }}$ was computed using the projected CDDs and $S_{0}$ using CDDs for the year 2005.

\subsection{Projecting energy prices}

To estimate average current household heating expenses we took the residential retail energy prices for the most recent year available at the state level (EIA 2005a,b,c). We obtained the percentage of households in each state using each of the energy sources as their primary heating fuel in 2005, multiplied the 2005 prices by these percentages, and summed these products for a total average heating price (in US dollars per mbtu or MJ). For cooling prices, we used the 2005 retail electricity prices, converted into dollars per mbtu or MJ. For future prices, we used the residential high price series of the US Energy Information Administration (EIA 2005d) for each major energy source. We averaged these prices over decades, calculated the average inter-decadal price change, and applied these projected changes to the 2005 base state prices over decades through the 2090s for a state-specific high price series. Projected prices were weighted by the percentage of households in each state using each as a primary heating source, and these products summed for projected total heating prices for each state.

\subsection{Estimating total $\mathrm{HC}$ energy use and $\mathrm{CO}_{2}$ emissions}

Since roughly 3 units of energy are required to generate each unit of energy of electricity consumed, we multiplied projected on-site electricity usage by 3 to estimate total energy use for electricity. We obtained carbon dioxide emission rates for site-combusted heating fuels (in pounds per mbtu or MJ) (EPA Inventory 2006) and for average state electricity (EIA 2005e), amended by including an additional $6.5 \%$ energy lost in transmission. We multiplied these rates by our projected HC usages to estimate future GHG emissions.

\subsection{Modeling fuel-switching and upgrades}

We modeled fuel-switching from heating fuels to electric heat in 2 ways. In both we first identified in which future decade the projected price of each fuel rose above that of retail residential electricity in the high price series. In the first approach, we simply shifted the heating oil and liquid petroleum gas (LPG) btu or MJ to additional electric usage. However, each state had significant differences among the heating intensities of the 3 sources. So, in the second approach we multiplied the mbtu or MJ of the fuels in each future decade that met the price criteria by the ratio of their heating intensity to that of electricity. Selecting between the 2 is problematic: we do not know what portion of the HI differences is due to inherent differences between furnaces and electrical heating systems, and what portion is due to factors historically associated with homes employing these systems (e.g. age of building). We used the average of these 2 procedures and calculated impacts on HC expense, total usage, and GHG emissions accordingly.

To estimate impacts of HC upgrades, we consulted with modelers who have developed 2 of the most widely respected web-based home energy calculators (EPA's Energy Star Home Energy Yardstick and Lawrence Berkeley National Laboratory's Home Energy Saver), designed to estimate savings based on user inputs of usage, equipment, and building characteristics. Given the great variability of these parameters, averaging potential savings across the region is obviously problematic. The modelers' best guess was that a 'regional average' household could save $30 \%$ on combined on-site heating-and-cooling energy use through investments in insulation and more efficient HC com- 
ponents (e.g. furnaces and ACs). None of them included changes in everyday behaviors (e.g. thermostat settings) in their models or estimates. We multiplied our projected on-site usages by 0.70 and then recalculated HC expense, total usage, and GHG emissions accordingly.

\section{RESULTS}

\subsection{HC expense savings from high climate change}

Fig. 1 shows the projected average annual savings in household HC expenses due to high climate change, with modeled increases in AC saturation and under the extrapolated high price series, for 3 sub-regions of the northeastern US: Northern Tier (ME, NH, VT), Central (MA, RI, CT, NY, NJ, PA, WV) and Southern Tier (MD,

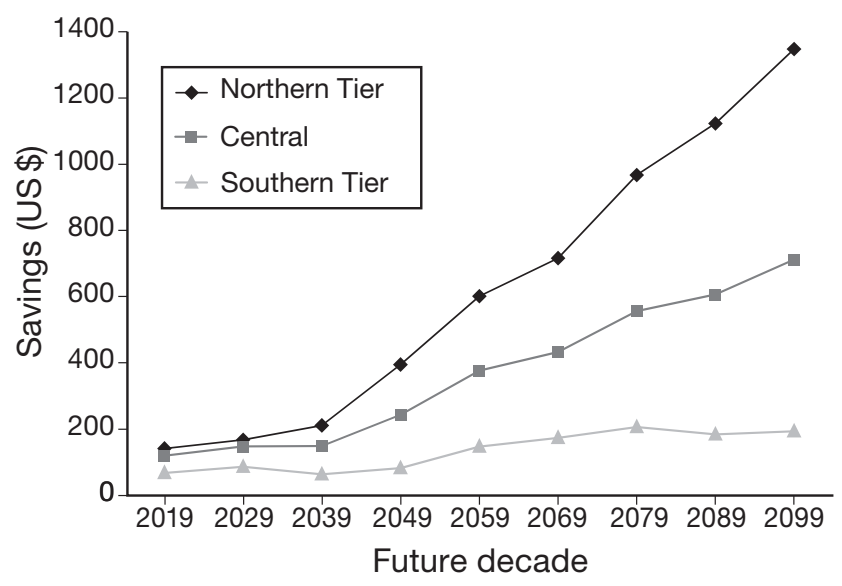

Fig. 1. Average annual savings (in 2004 US \$) in heating and cooling expense over present usage resulting from high climate change, with increased air conditioning saturation and high price series, by sub-region in the northeastern US. Note that present usage is taken to be 2000-2006 average degreedays multiplied by 2005 intensities; these usages then multiplied by extrapolated Energy Information Administration (EIA)-projected high prices for each future decade

Table 2. Correlations $\left(r^{2}\right.$; parentheses: $\left.p\right)$ of population-weighted state average 1971-2000 temperature normals with factors determining climate change impacts on heating-plus-cooling expense. HDD: heating degree-days; CDD: cooling degree-days; ns: not significant; na: not applicable

\begin{tabular}{|lcc|}
\hline & $\begin{array}{c}\text { Expected to reduce costs/ } \\
\text { increase savings }\end{array}$ & $\begin{array}{c}\text { Expected to increase costs/ } \\
\text { reduce avings }\end{array}$ \\
\hline Degree-day change & HDD decrease & CDD increase \\
& $-0.971(0.000)$ & $0.869(0.000)$ \\
Energy intensities & Heating intensity & Cooling intensity \\
& ns & $0.925(0.000)$ \\
Energy prices & Increase in heating price & Increase in cooling price \\
& $-0.924(0.000)$ & na \\
\hline
\end{tabular}

DE, VA), weighted by population in 2000. Savings are relative to 'present usage' — taken to be 2000-2006 average degree-days multiplied by 2005 intensities multiplied by extrapolated EIA-projected high prices for each future decade, i.e. usage is held constant and prices are allowed to increase as projected.

Sub-regional differences in these projected savings are clear and require an explanation. In Table 1, we summarized the factors that determine the valence and extent of climate change impact on HC expenses. Table 2 shows the correlations of 1971-2000 population-weighted state-level normal temperatures with these factors.

Eq. (1) states that HC expense savings from climate change vary directly with rate of HDD decrease and inversely with the rate of CDD increase; both rates are projected to vary among the 13 states along a northsouth gradient. The average population-weighted normal temperature (1971-2000) of a state has a strongly negative correlation $\left(\mathrm{R}^{2}\right)$ with the average projected inter-decadal decrease in HDDs over the coming 9 decades under high climate change $\left(\mathrm{r}^{2}=-0.971\right.$, $\mathrm{p}=0.000$ ), and a strongly positive correlation with the average increase in CDDs $(0.869,0.000)$. Locales with baseline temperatures below indoor comfort levels will experience a greater portion of warming as a decrease in heating degree-days; those with baseline temperatures exceeding comfort levels will experience a greater portion as an increase in cooling degree-days.

$\mathrm{HC}$ expense savings from climate change also vary directly with heating intensity and inversely with cooling intensity (Eq. 1). We divided our estimated household usages for 2005 by the standard $65^{\circ} \mathrm{F}\left(16.8^{\circ} \mathrm{C}\right)$ based degree-days of that year to estimate these indexes. State temperature normals (1971-2000) have a strongly positive correlation with cooling intensity $\left(\mathrm{r}^{2}\right.$ $=0.925, \mathrm{p}=0.000$ ) and a positive, but insignificant correlation with heating intensity $\left(\mathrm{r}^{2}=0.390\right)$. While households with colder winters in our region have had greater incentive to invest in insulation and heating efficiency, they have also inherited older housing stock and HC equipment. Households with hotter summers have experienced a convergence of factors encouraging increased ownership and use of ACs and thereby increased cooling intensity: lower electricity prices; and higher rates of new home construction, percentage of single-family units and average home square footage, each associated with greater AC use.

Finally, HC expense savings from climate change vary directly with increases in heating energy price and inversely with increases in cooling energy 
price (Eq. 1) and state temperature normals have a strongly negative correlation with projected interdecadal change in heating price $\left(\mathrm{r}^{2}=-0.924, \mathrm{p}=\right.$ 0.000). This is because the normals are negatively correlated with the percentage of households heating with petroleum-based fuels $(-0.906,0.000)$, and these prices are projected to rise far faster than electricity prices. This conjunction of inherited patterns of home heating systems and energy markets is the third factor that increases the likelihood that state-average household HC savings from climate change will vary with latitude, at least in this region. Table 2 summarizes the correlations of 1970-1999 normals with factors determining climate change impacts on heating-plus-cooling expense.

\subsection{Other impacts and behavioral alternatives}

Table 3 presents raw projections of high climate change alone and with 3 actions (increased AC saturation, shift to lower-cost electric heating, and upgrades) on $3 \mathrm{HC}$ variables of potential concern (expenses; total energy use, and $\mathrm{CO}_{2}$ emissions). Table 4 presents these as percent savings of 'present usage': 2000-2006 average degree-days multiplied by 2005 intensities. For expense savings, these usages are multiplied by extrapolated EIA-projected high prices for each future decade. Numbers in bold are 'negative savings': increases in these variables. Fig. 2 presents annual savings high-climate change (HCC) alone, of $\mathrm{HCC}$ with AC saturation, and of $\mathrm{HCC}, \mathrm{AC}$ saturation and

Table 3. Impacts of 4 behavioral options under high climate and price change. HC: heating and cooling; AC: airconditioning

\begin{tabular}{|c|c|c|c|c|c|c|c|c|c|c|}
\hline & & \multicolumn{3}{|c|}{$\begin{array}{l}\text { HC expenses } \\
\left(2004 \text { US } \$ \text { household }{ }^{-1} \mathrm{yr}^{-1}\right)\end{array}$} & \multicolumn{3}{|c|}{$\begin{array}{l}\text { Total HC energy } \\
\left(\mathrm{MJ}_{\text {household }}^{-1} \mathrm{yr}^{-1}\right)\end{array}$} & \multicolumn{3}{|c|}{$\begin{array}{c}\mathrm{CO}_{2} \text { emissions } \\
\text { (t household }{ }^{-1} \mathrm{yr}^{-1} \text { ) }\end{array}$} \\
\hline \multirow{11}{*}{$\begin{array}{l}\text { No action: } \\
\text { high climate } \\
\text { change alone }\end{array}$} & & North & Central & South & North & Central & South & North & Central & South \\
\hline & $2000-06$ & 1098 & 1020 & 933 & 81.4 & 78.0 & 99.0 & 4.61 & 4.18 & 5.59 \\
\hline & $2010 \mathrm{~s}$ & 1146 & 1016 & 925 & 72.7 & 73.9 & 99.5 & 4.07 & 3.91 & 5.59 \\
\hline & $2020 \mathrm{~s}$ & 1308 & 1054 & 916 & 72.5 & 72.6 & 98.6 & 4.05 & 3.83 & 5.54 \\
\hline & $2030 \mathrm{~s}$ & 1455 & 1124 & 957 & 71.8 & 73.6 & 101.7 & 4.00 & 3.88 & 5.72 \\
\hline & $2040 \mathrm{~s}$ & 1441 & 1065 & 929 & 64.3 & 67.9 & 101.6 & 3.55 & 3.55 & 5.72 \\
\hline & $2050 \mathrm{~s}$ & 1414 & 987 & 869 & 57.8 & 61.8 & 98.2 & 3.17 & 3.21 & 5.53 \\
\hline & $2060 s$ & 1476 & 984 & 851 & 55.8 & 60.5 & 98.5 & 3.04 & 3.12 & 5.55 \\
\hline & $2070 s$ & 1398 & 904 & 816 & 49.6 & 56.4 & 100.6 & 2.66 & 2.88 & 5.67 \\
\hline & $2080 s$ & 1415 & 901 & 838 & 47.4 & 57.1 & 109.3 & 2.51 & 2.89 & 6.17 \\
\hline & $2090 s$ & 1362 & 845 & 834 & 43.8 & 55.4 & 115.2 & 2.28 & 2.78 & 6.50 \\
\hline \multirow{9}{*}{$\begin{array}{l}\text { High climate } \\
\text { change with } \\
\text { increasing AC } \\
\text { saturation }\end{array}$} & $2010 s$ & 1165 & 1026 & 928 & 74.3 & 74.8 & 100.0 & 4.10 & 3.95 & 5.61 \\
\hline & $2020 s$ & 1331 & 1071 & 927 & 74.4 & 74.1 & 100.1 & 4.09 & 3.90 & 5.63 \\
\hline & $2030 s$ & 1481 & 1143 & 968 & 73.9 & 75.3 & 103.4 & 4.04 & 3.95 & 5.81 \\
\hline & $2040 s$ & 1489 & 1121 & 968 & 68.5 & 72.9 & 107.5 & 3.65 & 3.78 & 6.05 \\
\hline & $2050 s$ & 1475 & 1061 & 921 & 63.2 & 68.6 & 106.4 & 3.29 & 3.52 & 6.00 \\
\hline & $2060 s$ & 1553 & 1078 & 913 & 62.7 & 69.1 & 108.6 & 3.19 & 3.52 & 6.13 \\
\hline & $2070 s$ & 1494 & 1027 & 899 & 58.3 & 68.0 & 114.4 & 2.86 & 3.41 & 6.46 \\
\hline & $2080 s$ & 1531 & 1050 & 939 & 58.2 & 71.5 & 126.9 & 2.75 & 3.56 & 7.17 \\
\hline & $2090 s$ & 1499 & 1018 & 948 & 56.8 & 72.5 & 135.7 & 2.57 & 3.57 & 7.67 \\
\hline \multirow{9}{*}{$\begin{array}{l}\text { High climate } \\
\text { change with } \\
\text { increasing AC } \\
\text { saturation, and } \\
\text { switching from } \\
\text { heating fuels to } \\
\text { electric heat }\end{array}$} & $2010 s$ & 1166 & 1025 & 932 & 74.3 & 75.5 & 103.1 & 4.10 & 3.98 & 5.68 \\
\hline & $2020 \mathrm{~s}$ & 1333 & 1067 & 928 & 74.4 & 75.0 & 103.2 & 4.09 & 3.93 & 5.68 \\
\hline & $2030 s$ & 1484 & 1137 & 916 & 73.9 & 76.3 & 111.7 & 4.04 & 3.98 & 5.90 \\
\hline & $2040 s$ & 1489 & 1112 & 912 & 71.0 & 78.1 & 115.1 & 3.70 & 4.01 & 6.13 \\
\hline & $2050 \mathrm{~s}$ & 1453 & 1029 & 866 & 73.7 & 74.2 & 113.1 & 3.30 & 3.66 & 6.06 \\
\hline & $2060 s$ & 1433 & 1037 & 853 & 127.5 & 74.3 & 114.9 & 3.29 & 3.65 & 6.19 \\
\hline & $2070 s$ & 1278 & 957 & 851 & 114.6 & 75.1 & 120.2 & 2.95 & 3.51 & 6.51 \\
\hline & $2080 s$ & 1226 & 972 & 901 & 110.8 & 77.9 & 132.6 & 2.84 & 3.65 & 7.21 \\
\hline & $2090 s$ & 1136 & 908 & 918 & 103.5 & 80.7 & 141.3 & 2.64 & 3.60 & 7.71 \\
\hline \multirow{9}{*}{$\begin{array}{l}\text { High climate } \\
\text { change with } \\
\text { increasing AC } \\
\text { saturation, and } \\
\text { conservation } \\
\text { upgrades }\end{array}$} & $2010 s$ & 816 & 718 & 650 & 52.0 & 52.3 & 70.0 & 2.87 & 2.77 & 4.46 \\
\hline & $2020 \mathrm{~s}$ & 932 & 750 & 649 & 52.1 & 51.9 & 70.1 & 2.86 & 2.74 & 4.48 \\
\hline & $2030 s$ & 1036 & 800 & 678 & 51.7 & 52.7 & 72.4 & 2.83 & 2.78 & 4.60 \\
\hline & $2040 s$ & 1043 & 785 & 678 & 47.9 & 51.1 & 75.3 & 2.55 & 2.65 & 4.82 \\
\hline & $2050 \mathrm{~s}$ & 1033 & 743 & 645 & 44.2 & 48.0 & 74.5 & 2.30 & 2.46 & 4.82 \\
\hline & $2060 s$ & 1087 & 754 & 639 & 43.9 & 48.4 & 76.0 & 2.23 & 2.46 & 4.90 \\
\hline & $2070 s$ & 1046 & 719 & 629 & 40.8 & 47.6 & 80.1 & 2.00 & 2.38 & 5.24 \\
\hline & $2080 s$ & 1072 & 735 & 658 & 40.8 & 50.1 & 88.8 & 1.93 & 2.47 & 5.81 \\
\hline & $2090 s$ & 1049 & 712 & 664 & 39.7 & 50.7 & 95.0 & 1.80 & 2.47 & 6.22 \\
\hline
\end{tabular}


Table 4. Percent savings of behavioral options relative to 'the present'. HC: heating and cooling; AC: air conditioning. Calculations based on $\mathrm{HC}$ expense: $2004 \mathrm{US} \$$ household ${ }^{-1} \mathrm{yr}^{-1}$; total energy: MJ household ${ }^{-1} \mathrm{yr}^{-1}$; $\mathrm{CO}_{2}$ emissions: $\mathrm{t}_{\text {household }}^{-1} \mathrm{yr}^{-1}$

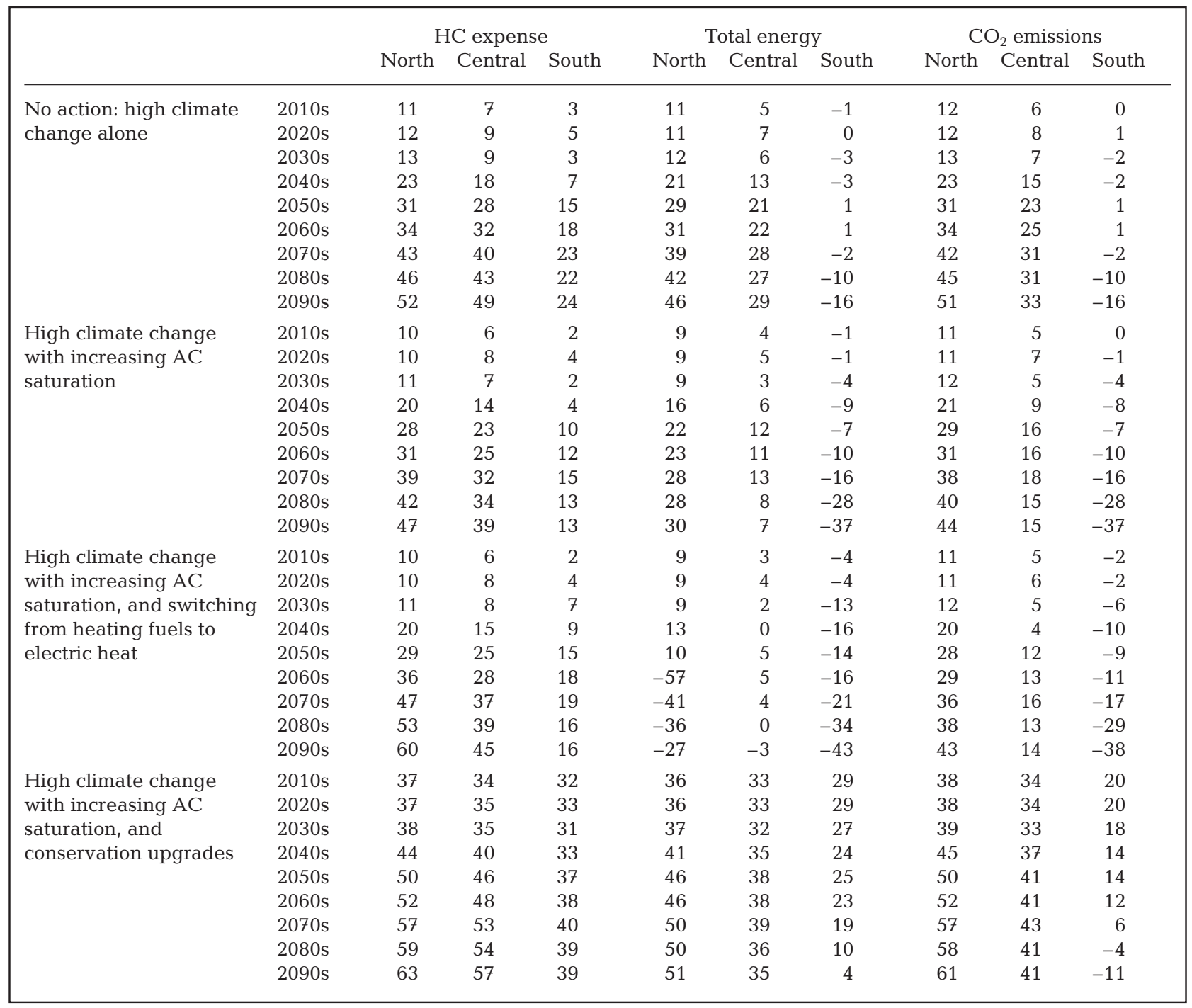

fuel switching on the 3 variables of concern, averaged over 90 yr.

Several patterns are worth noting. First, in each subregion and behavioral option, the climate changeinduced savings relative to present usage are greatest for $\mathrm{HC}$ expenses, less for $\mathrm{CO}_{2}$ and least for total $\mathrm{HC}$ energy. In the Southern Tier high climate change increases both $\mathrm{HC}$ energy use and $\mathrm{CO}_{2}$ emissions in each decade and for each non-upgrade behavioral option, despite expense savings increasing to $24 \%$ over the century. Greater non-expense costs of climate change in the Southern Tier are due to its greater use of electric heating and its greater use of coal for electricity generation (Fig. 3). This is similar to findings of Huang (2006) and Hadley et al. (2006). Second, while increasing $\mathrm{AC}$ saturation reduces expense savings only slightly and fuel switching increases them again, both of these behaviors reduce savings in $\mathrm{CO}_{2}$ and total energy more dramatically. The exception to both is $\mathrm{CO}_{2}$ in the Northern Tier. The portion of electricity generated from coal-burning in the Northern Tier is roughly one-seventh the portion in the Southern Tier, while the Northern Tier portion from nuclear and hydro is over $70 \%$ more than the Southern Tier portion. (EIA 2005f).

Finally, modeled upgrades entail the greatest savings in each of the 3 impacts of potential concern under both modeled high climate change and modeled low climate change. For the latter we applied the average projected monthly mean temperatures of the 2 GCMs showing the lowest rate of change under the lower emissions scenario (Max Planck Institute for Meteorol- 


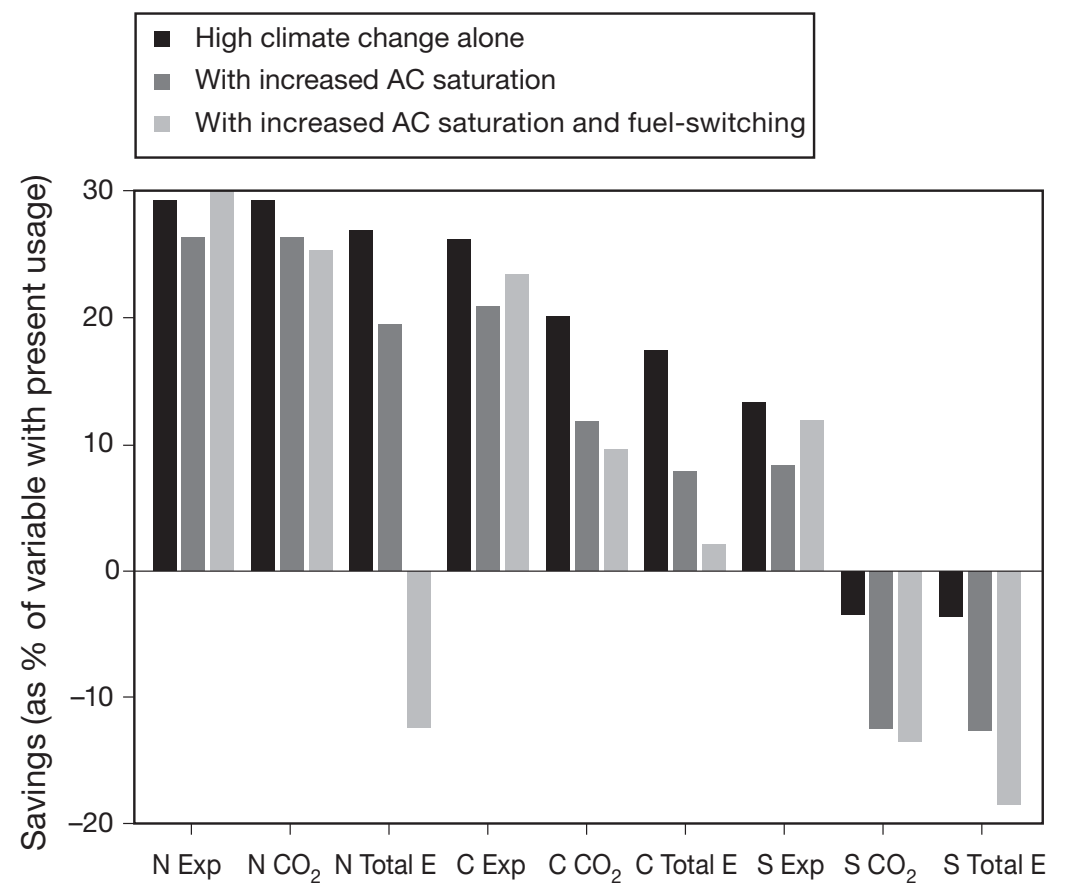

Fig. 2. Average annual savings (\%) over present usage, averaged over 2010 to 2099, by sub-region in the northeastern US: high climate change alone, with increased air-conditioning (AC), and with fuel-switching. Note that present usage is taken to be 2000-2006 average degree-days multiplied by 2005 intensities. For expense savings, these usages are multiplied by extrapolated Energy Information Administration (EIA)-projected high prices for each future decade. N: Northern Tier; C: Central Tier; S: Southern Tier; Exp: expenses; Total E: total energy

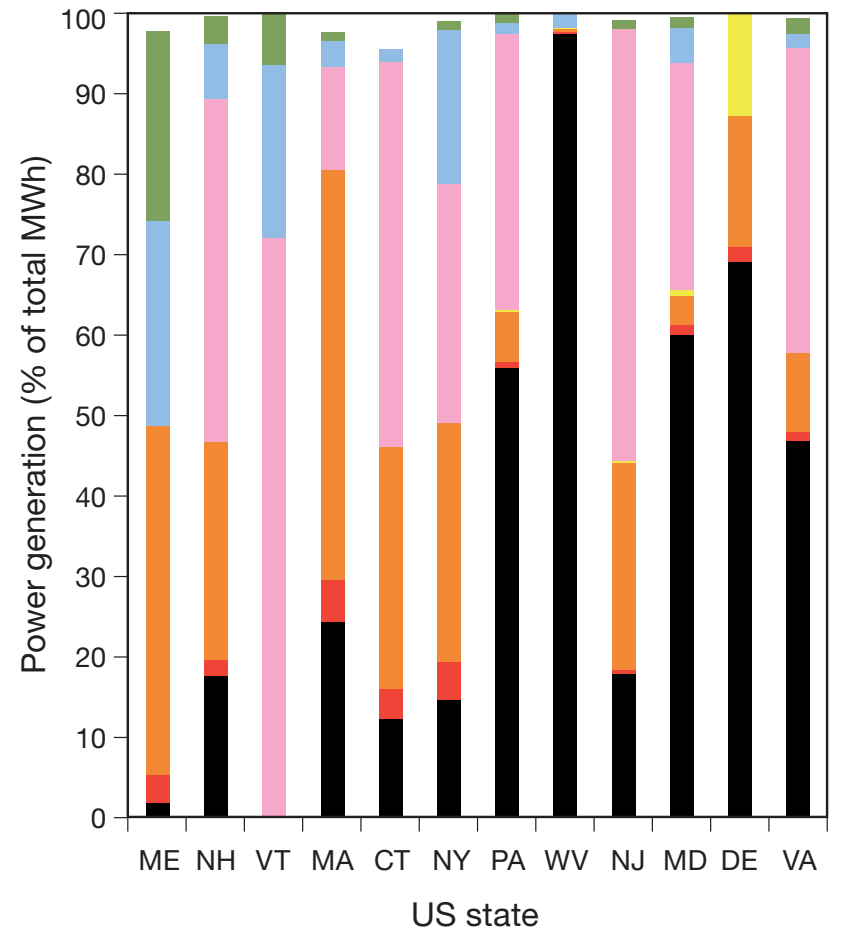

\begin{tabular}{|ll|}
\hline Wood \& other biomass & Natural gas \\
Hydroelectric & Petroleum \\
Nuclear & Coal \\
Other gases & \\
\hline
\end{tabular}

Fig. 3. Electric power industry generation by primary energy source, 2006, as percentage of total MWh (from EIA 2008) ogy [ECHM] and National Center for Atmospheric Research [NCAR], Scenario B2), and followed the same procedures as we did for our high projections. Fig. 4 shows projected HC expense savings from upgrades under both low and high climate change, with increased AC saturation. To compare the extent of upgrade advantages across impacts, decades, climate change series and behavioral alternatives, we divided the savings by the present value (2005) of that variable. Across the 324 resulting cells, the upgrade advantage ranged between 3 and $130 \%$; the median was 29 , the average $32 \%$.

\section{LIMITS TO THE ANALYSIS}

Further research in each component will improve the accuracy of these projections. While it is unlikely that projections of relative humidity, windiness and cloud cover will improve sufficiently over the next few years to be included in these models, we should see progress in the evaluation of the GCMs in retrodicting temperature change. Improved modeling of temperature variation within months is critical in projecting future summer peak electricity demand, which will affect both usage and prices. Each year of aggregate state-level energy use data allows further refinement of the climate-sensitivity modeling pioneered by Belzer and his colleagues (1996). While one of the authors built a model of dynamic sensitivities based on changes over the previous 23 yr (Amato 2004), we elected not 


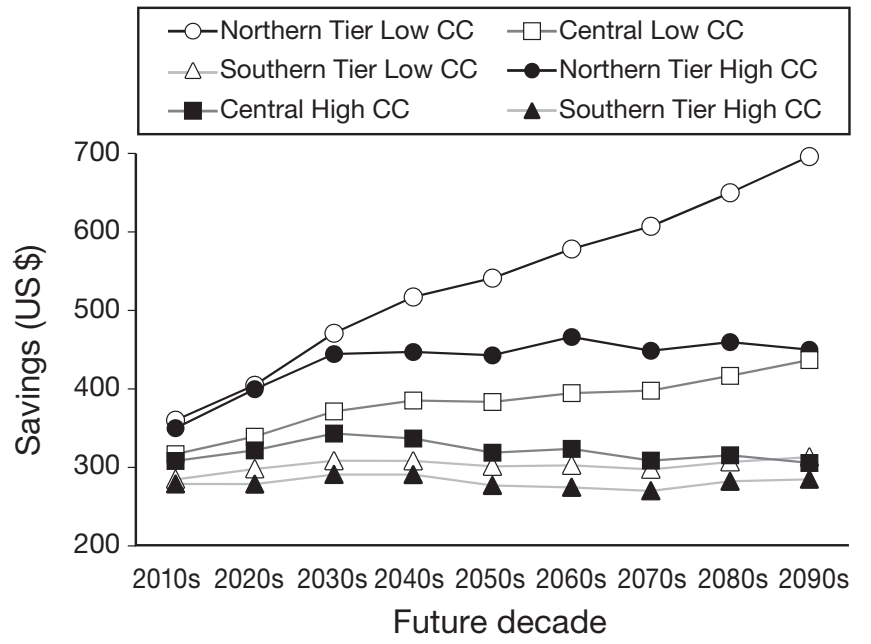

Fig. 4. Average annual savings (in 2004 US \$) in heating and cooling expenses from upgrades over 'wait and see' under high and low climate change (CC), high price change, increased air conditioning saturation, by sub-region in the northeastern US

to model future aggregate changes in $\mathrm{HC}$ intensities, a decision we address in our 'Discussion'. It is hard to imagine that significant progress will be made in projecting energy prices beyond a few weeks, given their high volatility.

The number of variables in our model (degree-days, intensities, energy prices, percent of households heating with different fuels, composition of each state's residential electricity generation, GHG emission rates from these energy sources) as well as the number of states and decades, make a full sensitivity analysis beyond our present means. However, it is worth highlighting the relevance of changing rates in these variables for 2 findings most directly relevant to household HC decisions.

\subsection{Is it worth investing in $\mathrm{HC}$ conservation upgrades?}

The primary household decision affected by the research is whether to make HC upgrade investments in a context of climate change, i.e. 'if projected climate change is likely to reduce my heating bills, is it (still) worth making investments in conservation upgrades?' Since we ran our models, one variable has shown dramatic change. The price per gallon (ca. 3.78 l) of heating oil in the region increased over 3-fold between the winter of 1997-1998 and the winter of 2007-2008. If this rate of increase were sustained over the next couple of decades, the 'high' price projections of the US Energy Information Agency would significantly undershoot the mark, as would our estimates of average annual savings from projected high climate change based on them.

However, Eq. (1) states that heating energy price increases affect household heating expense via both changes in HDD and changes in HI. These mediators of heating price affect household upgrade investment decisions in opposite directions. On the one hand, increasing heating energy prices increase the heatingexpense savings from each climate-change driven reduction in $H D D$, thereby reducing the incentive to initiate upgrade investments. At the same time, increasing heating energy prices increase the heatingexpense savings from each upgrade reduction in heating intensity, increasing the incentive to initiate these investments. The critical question in determining the impact of heating-price increases on upgrade decisions is the relative size of these 2 other rates of change: HDD vs. heating intensity. Our estimates are that the percent decreases in heating usage from projected high climate change over the next 2 or 3 decades, at a sub-regional and decadal average annual, will only reach $13 \%$ in the 2030s: significantly lower than the HC usage savings experts estimate are achievable by upgrade investments made in a year or two $(30 \%)$. As these investments will provide both greater and more rapid $\mathrm{HC}$ expense savings than 'waiting for global warming to lower my utility bills', they continue to make good sense in the face of climate change. How robust is this conclusion if variables change at rates beyond those modeled here?

Table 5. Decadal average annual savings (US\$) in heating expenses from upgrade investments, average household in Maine, varying rates of climate, energy price and usage reduction (UR). EIA: Energy Information Administration

\begin{tabular}{|c|c|c|c|c|c|c|}
\hline \multirow[t]{3}{*}{ Decade } & \multicolumn{6}{|c|}{ Heating usage reductions with: } \\
\hline & \multicolumn{3}{|c|}{ Low climate change } & \multicolumn{3}{|c|}{ High climate change } \\
\hline & $20 \%$ UR & $30 \%$ UR & $40 \%$ UR & $20 \%$ UR & $30 \%$ UR & $40 \%$ UR \\
\hline \multicolumn{7}{|c|}{ With modeled EIA 'high' price projections } \\
\hline $2010 s$ & 232 & 347 & 463 & 223 & 335 & 446 \\
\hline $2020 s$ & 264 & 396 & 529 & 261 & 392 & 523 \\
\hline $2030 s$ & 311 & 466 & 622 & 294 & 440 & 587 \\
\hline \multicolumn{7}{|c|}{$200 \% \mathrm{~d}^{-1}$ heating price increase } \\
\hline $2010 s$ & 385 & 578 & 770 & 371 & 557 & 743 \\
\hline $2020 s$ & 753 & 1129 & 1505 & 744 & 1116 & 1488 \\
\hline $2030 s$ & 1548 & 2322 & 3097 & 1462 & 2193 & 2924 \\
\hline \multicolumn{7}{|c|}{$300 \% \mathrm{~d}^{-1}$ heating price increase } \\
\hline $2010 s$ & 578 & 867 & 1156 & 557 & 836 & 1114 \\
\hline $2020 \mathrm{~s}$ & 1693 & 2540 & 3387 & 1674 & 2511 & 3348 \\
\hline $2030 \mathrm{~s}$ & 5225 & 7838 & 10451 & 4934 & 7400 & 9867 \\
\hline
\end{tabular}


Table 5 summarizes decadal average annual savings in heating expenses from upgrade investments for the average household in Maine, the state with the highest estimated average household HC expense savings from high climate change, over the next 3 decades. Three factors are varied: climate change (our modeled low and high); heating energy price change (our extrapolation of EIA 'high price' series, a $200 \%$ per decade increase and a $300 \%$ per decade increase); and usage reductions from conservation upgrades (our modeled $30 \%$ as well as 20 and $40 \%$ ).

Through the 2030s, changing from low to high climate change reduces these savings very little: a maximum of $6 \%$ in the 2030s. However, changing the rates of heating price increase from our extrapolated EIA rate to a doubling per decade increases upgrade savings nearly 4 -fold, and changing it to a trebling per decade increases these savings nearly 16 -fold. Reducing upgrade percent usage reductions from our modeled $30 \%$ down to $20 \%$ reduces heating expense savings by $33 \%$. Although this is a significant decrease, with a minimum annual savings of between $\$ 200$ and $\$ 300$ (high climate change, modeled price change), upgrade investments will still pay for themselves within a few years. The higher the rate of heating energy price increase, the greater the impact of differences in upgrade usage-reduction differences on expense savings.

\subsection{Should I switch to lower-priced electric heat?}

The second household decision potentially affected by our findings is whether to switch from on-site heating fuel to lower-cost electric heat. Our research finds that this switch will have widely varying impacts on total $\mathrm{HC}$ expenses (from $2 \%$ over the next decade in southernmost states to over $60 \%$ at century's end, in northermost states), and will, at the same time entail consistently lower savings, and in many cases, increases (of up to $40 \%$ ), in both total HC energy used and in their GHG emissions. How robust are these findings?

The faster the rate of price increase in heating oil, LPG and natural gas (NG) relative to residential electricity (in dollars per on-site btu), the greater the expense savings from fuel-switching, and the sooner it will be financially attractive, especially for those with high heating usages (through high HDDs and/or high heating intensity). Because the energy lost in electricity generation and transmission is accepted as an engineering given, the increases in total energy usage (as opposed to on-site) would remain in effect regardless of the fuels used to generate electricity. On the other hand, GHG emissions estimates are clearly affected by changes in the energy sources tapped to generate electricity. Any shift from oil, NG and especially coal combustion towards nuclear, hydro, solar or wind would reduce GHG emissions from electricity, and therefore the emissions entailed by shifting to electric heat. Such shifts in the sources of electricity may be profoundly affected by policy decisions and difficult to predict. Whatever the future mixes of electricity, a larger message is valid: switching from onsite heating fuel to electric heat has resource and environmental impacts that deserve greater attention and consideration.

\subsection{Financial crisis and economic recession}

The current financial crisis, as well as the preceding economic downturn, which it may well exacerbate, have diminished the prospects for employment, purchasing power, and credit for the majority in this the Northeastern US. This is likely to affect the implications of our modeled results in 4 ways. First, it is likely to increase the fiscal importance of climate-changedriven HC expense savings to households. Second, it is likely to make switching from home heating oil and LPG to lower cost electric heat attractive to more households and earlier. Third, while it is likely to increase the fiscal importance of $\mathrm{HC}$ expense savings resulting from conservation, it also likely to increase the financial barriers to initiate those measures requiring investments of money, i.e. the upgrades modeled here.

Projecting temperature and energy price changes will remain highly uncertain endeavors. However, several relationships in these projections are likely to be valid regardless of changes in these projections. First, $\mathrm{CC}>\mathrm{HC}$ expense savings at the state-average household level will vary inversely with historic temperature normals (i.e. directly with degrees latitude), because the colder the locale, the greater the portion of temperature increase that will be experienced as a decrease in HDDs, the smaller the portion as an increase in CDDs. Second, climate change will provide greater savings in $\mathrm{HC}$ expenses than in total energy or in $\mathrm{CO}_{2}$ emissions because (1) electricity prices are likely to rise less than petroleum prices; (2) the 3-fold difference between net and total energy pertains only to electricity, the sole source for cooling but only a partial source for heating; and (3) coal is likely to remain an important source of electricity in the region, and to have higher $\mathrm{CO}_{2}$ emission rates than other sources. Third, it is likely that petroleum-based fuel prices will increase significantly more than HDDs will decrease over the next 3 decades. 


\section{DISCUSSION}

The primary implications of these likely more robust projections are as follows: (1) households in northern states will receive the greatest financial benefits from climate change; (2) utility bills will not reflect the energy and GHG costs of these impacts; (3) climate change-driven savings on all 3 impacts of potential concern ( $\mathrm{HC}$ expense, total usage, and $\mathrm{CO}_{2}$ emissions) will be least, and those from upgrade investments will be most, over the next 2 or 3 decades.

Heating and cooling intensities (HI and CI) directly affect all 3 variables of potential concern and, unlike changes in energy prices and global climate change, they are variables over which individuals can exercise significant direct control. In mediating between daily behaviors and energy use and impacts, they parallel the measure of miles-per-gallon, but include a greater range of behavioral influences. They deserve wider attention. Their pivotal status leads us to consider the wisdom of including their aggregate projections in $\mathrm{CC}>\mathrm{HC}$ models. What is a householder to make of projected aggregate changes in $\mathrm{HI}$ and CI over future decades, similar to forecasts of changes in temperature and price? If these intensity projections show significant reductions (increased efficiency), then there is little perceived incentive for upgrade investments and/or behavioral change. If they show an insignificant increase, there appears to be little hope for these changes. We provide clearer and more useful decisionmaking tools if we hold present intensities constant (insuring that they are as current and accurate as possible) in models of projected temperature and price change, and then model the impacts of several specific choices affecting these intensities that the household can make over the near future.

Inter-household differences in $\mathrm{HI}$ and $\mathrm{CI}$ are a key research frontier. A knowledge of these differences can help guide programs of energy conservation: the greatest gains from upgrades will be in those households with especially high HI or CI. There is likely to be an inverse correlation between household income and $\mathrm{HI}$ : lower income households are more likely to live in older buildings that have experienced minimal retrofits, and a considerable portion are comprised of seniors, who tend to set their thermostats higher than younger neighbors (Liao \& Chang 2002). The only factor in $\mathrm{HI}$ or CI that is likely to be inversely proportional to income is the size of the home. Low-income households in more northern locales, especially those comprised of older people are likely to face (1) the largest raw savings from climate change, (2) the greatest fiscal importance of these savings, and (3) the greatest barriers to achieving significant upgrades via investments of money and/or labor.
HC intensity research is also critical in further development of web-based decision-tools for resident use. We need to know both the costs and the intensityreduction benefits of $\mathrm{HC}$ upgrades in homes with different baseline HC intensities and features to model the combined effects of degree-day and price changes on payback periods. It is worth recalling that the experts who estimated a $30 \%$ HC usage reduction resulting from conservation efforts included only investments in insulation and components and specifically excluded all other behavioral changes, e.g. thermostat settings, use of thermal curtains, windows, doors and shades. They all said that assuring strict compliance to daily behaviors, necessary for research on their impacts, was too difficult. The value of knowing the effects of energy behavior, however, argues for greater efforts here.

\section{CONCLUSIONS}

A common folk-theory, at least in the United States, is that the majority of household energy comsumers will only initiate significant efforts to mitigate environmental problems - including anthropogenic climate change - if and when the impacts of these problems on their own lives become so dire that they are 'forced' to do so. The case of $\mathrm{CC}>\mathrm{HC}$ impacts in northern latitudes challenges this view. Households are likely to receive financial benefits from a process to which they have contributed disproportionately and which is likely to degrade the health and livelihoods of many people in other regions and many species. Public communication of $\mathrm{CC}>\mathrm{HC}$ projections should take this challenge to a common folk theory as an opportunity. On their own, prices do not reflect full costs. On its own, the market does not avoid harm, or assign or accept responsibility. Only people, through conscious deliberation and with adequate knowledge, can do this. Residential heating and cooling energy use is at once a domain of climate change impact and a domain of climate change responsibility. In both of these directions of influence, it occupies a place close to home. Good research, well communicated, would allow households to discuss and address an ancient and intimate concern-keeping the ones closest to us adequately sheltered - alongside a recent and global one: the mitigation of anthropogenic climate change.

Acknowledgements. This work was supported by the Global Change Research Program, Office of Research and Development, US Environmental Protection Agency (Cooperative Agreement R 83053301); the Human Dimensions of Global Change Program, Division of Social, Behavioral and Economic Sciences, US National Science Foundation; the 
Carnegie Mellon University Center for Integrated Study of the Human Dimensions of Global Change; and the Department of Agricultural Economics and Rural Sociology of Pennsylvania State University. We also thank A. Fisher and J. Shortle for their guidance and leadership of the Consortium for Atlantic Regional Assessment.

\section{LITERATURE CITED}

Amato AD (2004) Energy demand responses to temperature and implications of climate change. Doctoral dissertation, School of Public Affairs, University of Maryland, College Park, MD

Amato AD, Ruth M, Kirshen P, Horwitz J (2005) Regional energy demand responses to climate change: methodology and application to the Commonwealth of Massachusetts. Clim Change 71:175-201

Belzer DB, Scott MJ, Sands RD (1996) Climate change impacts on US commercial building energy consumption: an analysis using sample survey data. Energy Sources 18: $177-201$

Bord RJ, O'Connor RE, Fisher A (2000) In what sense does the public need to understand global climate change? Public Underst Sci 9:205-218

Christenson M, Manz H, Gyalistras D (2006) Climate warming impact on degree-days and building energy demand in Switzerland. Energy Convers Manag 47:671-686

Cubasch U, Meehl GA, Boer GJ, Stouffer RJ and others (2001) Projections of future climate change, Chap 9. In: Houghton JT, Ding Y, Griggs DJ, Noguer M, van der Linden PJ, Dai X, Makell K, Johnson CA (eds) Climate change 2001: the scientific basis. Cambridge University Press, New York, p 525-582

Diaz HF, Quayle RG (1980) Heating degree day data applied to residential heating energy consumption. J Appl Meteorol 3: 241-246

EIA (US Energy Information Administration) (2005) US electric power industry emissions by state. www.eia.doe.gov/ cneaf/electricity/epa/pat5p1.html

EIA (2005f) Annual energy review, Table 5. Electric power industry generation by primary energy source, 1990 through 2005. http://www.eia.doe.gov/oiaf/archive/aeo05/ index.html

EIA (2005a) Natural gas navigator; natural gas prices, residential sector. http://tonto.eia.doe.gov/dnav/ng/ng_pri_ sum_a_EPG0_PRS_DMcf_a.htm

EIA (2005b) Petroleum navigator; distillate \#2 prices, residential sector. http://tonto.eia.doe.gov/dnav/pet/pet_pri_dist_a_ EPD2_PRT_cpgal_a.htm

EIA (US Energy Information Administration) (2005c) Table 5.6.A. Average retail price of electricity to ultimate customers by end-use sector, by state. http://eia.doe.gov/cneaf /electricity/epm/epm_sum.html

EIA (2005d) Annual energy outlook. http://tonto.eia.doe.gov/ FTPROOT/multifuel/038405.pdf

EIA (2008) State electricity profiles, Table 5. Electric power industry generation by primary energy source, 1990 through 2006 (megawatthours). www.eia.doe.gov/fuelelectric.html

EPA (US Environmental Protection Agency) (2006) Inventory of U.S. greenhouse gas emissions and sinks: 19902005. Annex 2, Table A-30. www.epa.gov/climatechange /emissions/downloads06/07CR.pdf

Hadley SW, Erickson DJ, Hernandez JL, Thompson SL
(2004) Future U.S. energy use for 2000-2025 as computed with temperatures from a global climate prediction model and energy demand model. 24th USAEE/IAEE North American, Washington, DC. www.csm.ornl.gov/ fj7/USAEE_paper.pdf.

> Hohne N, Blok K (2005) Calculating historical contributions to climate change - discussing the 'Brazilian Proposal'. Clim Change 71:141-173

Huang J (2006) The impact of climate change on the energy use of the US residential and commercial building sectors. Lawrence Berkeley National Laboratory LBNL-60754, www.lbl.gov/Publications

> Kovats R, Ebi K (2006) Heatwaves and public health in Europe. Eur J Public Health 16:592-599

Liao H, Chang T (2002) Space heating and water heating energy demands of the aged in the U.S. Energy Econ 24: $267-284$

> Mendelsohn R, Dinar A, Williams L (2006) The distributional impact of climate change on rich and poor countries. Environ Dev Econ 11:159-178

> Muylaert MS, Cohen C, Rosa LP, Pereira AS (2004) Equity, responsibility and climate change. Clim Res 28:89-92

Najjar RG, Patterson L, Graham S (2007) Climate simulations of major estuarine watersheds in the Mid-Atlantic region of the United States. Clim Change doi: 10.1007/s10584-0089521-y. www.springerlink.com/content/eu17388390678268 /fulltext.pdf

National Climatic Data Center (2003) United States climate normals, 1971-2000 degree day computation methodology. www.docstoc.com/docs/879181/United-States/ClimateNormals-Degree-Day-Computation-Methology

O'Connor RE, Bord RJ, Yarnal B, Wiefek N (2002) Who wants to reduce greenhouse gas emissions? Soc Sci Q 83:1-17

Rosenthal DH, Gruenspecht HK (1995) Effects of global warming on energy use for space heating and cooling in the United States. Energ J 16:77-96

Sailor DJ (2001) Relating residential and commercial sector electricity loads to climate-evaluating state level sensitivities and vulnerabilities. Energy (Oxf) 26:645-657

Sailor DJ, Munoz JR (1997) Sensitivity of electricity and natural gas consumption to climate in the USA - methodology and results for eight states. Energy (Oxf) 22:987-998

Sailor DJ, Pavlova AA (2003) Air conditioning market saturation and long-term response of residential cooling energy demand to climate change. Energy (Oxf) 28:941-951

Sailor DJ, Rosen JN, Munoz JR (1998) Natural gas consumption and climate: a comprehensive set of predictive statelevel models for the United States. Energy (Oxf) 23: 91-103

Thom HCS (1954) The rational relationship between heating degree days and temperature. Mon Weather Rev 82:1-6

Thom HCS (1966) Normal degree days above any base by the universal truncation coefficient. Mon Weather Rev 94: $461-465$

US Census (2005) American fact finder. State fact sheets. http://factfinder.census.gov/home/saff/main.html?_lang=en

US Census (2005) American community survey. Table B25040. House heating fuel. http://factfinder.census.gov/servlet/ DTGeoSearchByListServlet?ds_name=ACS_2007_3YR_G0 0_\&_lang=en\&_ts $=254137513720$

Wu, SY, Najjar RG, Siewert J (2007) Potential impacts of sealevel rise on the mid- and upper-Atlantic region of the United States. Clim Change doi: 10.1007/s10584-0089522-x

Submitted: December 6, 2007; Accepted: October 22, 2008 Proofs received from author(s): March 6, 2009 